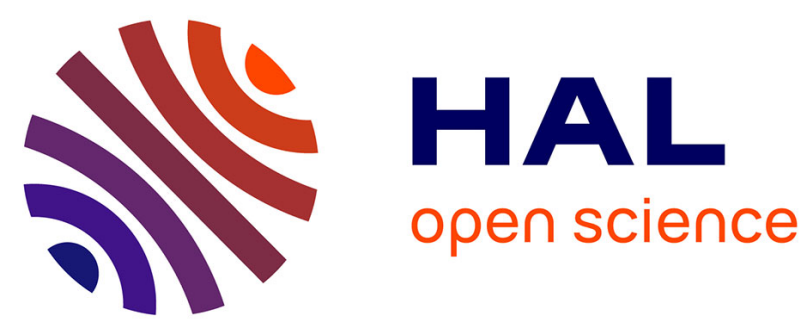

\title{
Effect of thermal cycles on the deformation state at the crack tip of crystallizable natural rubber
} Jean-Benoit Le Cam, Evelyne Toussaint, Olivier Dubois

\section{To cite this version:}

Jean-Benoit Le Cam, Evelyne Toussaint, Olivier Dubois. Effect of thermal cycles on the deformation state at the crack tip of crystallizable natural rubber. Strain, 2012, 48 (2), pp.153-156. 10.1111/j.14751305.2011.00807.x . hal-01131579

\section{HAL Id: hal-01131579 \\ https://hal.science/hal-01131579}

Submitted on 16 Mar 2015

HAL is a multi-disciplinary open access archive for the deposit and dissemination of scientific research documents, whether they are published or not. The documents may come from teaching and research institutions in France or abroad, or from public or private research centers.
L'archive ouverte pluridisciplinaire HAL, est destinée au dépôt et à la diffusion de documents scientifiques de niveau recherche, publiés ou non, émanant des établissements d'enseignement et de recherche français ou étrangers, des laboratoires publics ou privés. 


\title{
Effect of thermal cycles on the deformation state at the crack tip of crystallizable natural rubber
}

\author{
J.-B. Le Cam ${ }^{\mathrm{a}, 1}$, E. Toussaint ${ }^{\mathrm{b}}$ and O. Dubois ${ }^{\mathrm{a}}$ \\ ${ }^{a}$ CLERMONT UNIVERSITÉ, Institut Français de Mécanique Avancée, EA 386\%, \\ Laboratoire de Mécanique et Ingénieries, BP 10448, F-63000 \\ CLERMONT-FERRAND \\ ${ }^{\mathrm{b}}$ CLERMONT UNIVERSITÉ, Université Blaise Pascal, EA 3867\%, Laboratoire de \\ Mécanique et Ingénieries, BP 10448, F-63000 CLERMONT-FERRAND
}

\begin{abstract}
This paper deals with the effect of temperature variations on crack tip kinematics in rubbers, especially in crystallizing rubbers. In such materials, the high deformation level encountered at the crack tip engenders the formation of crystallites. As a consequence, the crack tip is reinforced and resists crack growth. However, this phenomenon is significantly affected by variations in material temperature. This is classically observed at the macroscopic scale in terms of crack propagation rate and path. In this study, the effect of temperature is studied at the local scale, by measuring the change in the kinematic field at the crack tip during thermal cycles. Results show that, in crystallizable natural rubber, the effect of temperature depends on the stretch ratio atained in the zone under consideration. In slightly stretched zones, the stretch ratio increases with the increase in temperature, whereas it decreases in highly stretched zones. This highlights the competition between the effects of
\end{abstract}


the variations in internal energy and in entropy on the thermomechanical response. Moreover, if crystallites form in highly stretched zones, the increase in temperature leads to crystallite melting, which increases the stretch ratio. This is explained by the fact that crystallites act as fillers by concentrating the stress and therefore by increasing the apparent stiffness of the material.

Key words: elastomer, crack growth, temperature effects, stress-induced crystallization, digital image correlation

\section{Introduction}

For sixty years, crack propagation in rubbers has remained an area of intensive research. Before the 1950s, no mechanical quantity available in the literature was considered as intrinsic to rubber failure. Indeed, the classical approach that consists in determining the elastic energy release rate is not appropriate; it is formulated within the framework of small deformations and requires the knowledge of either the stress field at the crack tip (available only from the 1970s) or the surface production (which remains difficult to measure without the full-field measurement method available only from the 1990s, see for instance ?)). This motivated the theoretical work of Rivlin and Thomas (1953), who proposed an energy-based approach to formulate tearing energy as the large strain counterpart to the elastic energy release rate. Then, from several kinds of notched sample geometry (Rivlin and Thomas, 1953; Thomas, 1960) tearing energy was measured using various methodologies (see the works of Rivlin and Thomas (1953); Greensmith and Thomas (1956) and Thomas (1958) under quasi-static loading and those of Thomas (1958) and Gent et al.

$\overline{1}$ Corresponding author lecam@ifma.fr Fax: $(+33) 473288027$ 
(1964) for cyclic loading). Therefore, using tearing energy, it became possible to study the influence of material formulation and loading conditions on crack propagation (Gent and Pulford, 1984; Hamed et al., 1996; Gent et al., 2003). Even if such an approach is now widely used, it remains a global approach and does not account for the thermophysical phenomena involved in crack growth. We consider that the improvement of crack growth prediction requires the identification of the physical mechanisms that occur and modify the kinematic field at the crack tip and in its vicinity during crack growth. For this purpose, the measurement of the mechanical fields in the crack tip vicinity seems to be an interesting line of investigation.

In this study, we focus on the effect of temperature on the kinematic field at the crack tip in crystallizable rubbers. In fact, the effect of the temperature is classically studied through crack propagation curves and the postmortem analysis of fracture surfaces. It is well known that temperature affects the relative contribution of phenomena such as knotty tearing, stick-slip and steady tearing (Greensmith and Thomas, 1956; Greensmith, 1956). The effect of temperature on crack propagation is therefore classically studied through variations in tearing energy and crack propagation rate. We believe that the understanding of temperature effects can be improved by analyzing them at the local scale through the variations in the kinematic field at the crack tip, and by linking them to phenomena due to thermoelastic couplings such as thermoelastic inversion, i.e. the competition between isentropic and entropic effects, and crystallite melting. To the best of our knowledge, no study has yet investigated quantitatively the effect of temperature on the kinematic field at the crack tip, and this is particularly the case for crystallizable material.

The aim of the present study is therefore to carry out such an analysis by mea- 
suring the displacement field at the crack tip during stretching using Digital Image Correlation (DIC) techniques, and then to apply thermal cycles. The first part of this paper presents the experimental set-up, the material formulation and mechanical properties, the testing machine and the measurement of the kinematic and thermal fields. The second part deals with the results obtained. Conclusions and perspectives close the paper.

\section{Experimental setup}

\subsection{Material and sample geometry}

The material considered here is a carbon black-filled natural rubber. It is denoted NR in the following. Table 1 summarizes the material formulation and gives some of its mechanical properties. The material was cured for 7 min, the mold temperature was set to 160 degrees $C$.

The stretch ratios at the beginning of crystallization and at the end of melting at 23 degrees $C$ were previously determined using volume change measurements (see Le Cam and Toussaint (2008, 2009)) and equal 1.64 and 1.44, respectively. A schematic view of the sample, whose geometry is $32 \mathrm{~mm}$ wide, $2 \mathrm{~mm}$ thick and $38 \mathrm{~mm}$ high, is presented in Figure 1. It was notched at its centre using a razor blade. The crack length was about $10 \mathrm{~mm}$. Once the crack was stretched, a heat source was applied to its interior. Further details are given in the next section. 


\subsection{Loading conditions}

The tests were carried out at ambient temperature under prescribed displacement using a MTS 858 Elastomer Test System testing machine. Its loading capacity is $15 \mathrm{kN}$ and the loading cell is $1 \mathrm{kN}$.

Samples were first stretched to a nominal stretch ratio equal to 1.88 at a strain rate set to $1.3 \mathrm{~min}^{-1}$. This level of stretch ratio ensured that we would obtain crack shape close to that of a circular hole of $10 \mathrm{~mm}$ diameter. A metallic cylinder of the same diameter, surrounded by a heater, was then inserted into the crack. A PT100 temperature sensor linked to a ProportionalIntegral-Derivative (PID) temperature controller enabled us to regulate the temperature precisely. Two thermal cycles were then performed between ambient temperature and 95 degrees $C$. This maximum temperature value was chosen in such a way that it led to the melting of all the crystallites formed in the bulk material (Marchal, 2006).

\subsection{Measurement of thermal and kinematic fields}

The kinematic field at the sample surface was obtained using the DIC technique. This consists in correlating the grey levels between two different images of a Region Of Interest (ROI) recorded using a cooled 12-bit dynamic Sensicam camera. Each image corresponds to different stretch ratio levels. This optical technique enabled us to reach a resolution of 0.03 pixels, corresponding to 1.02 $\mu m$ and a spatial resolution (defined as the smallest distance between two independent points) of 10 pixels, corresponding to $341 \mu \mathrm{m}$. Uniform lighting at the sample surface was ensured by a set of fixed lamps. The charge-coupled 
device $(\mathrm{CCD})$ of the camera had $1.410^{6}$ connected pixels $(1376 \times 1040)$. The software used for the correlation process was SeptD (Vacher et al., 1999).

Temperature measurements were carried out with a Cedip Jade III-MWIR infrared camera, which features a local plane array of $320 \times 240$ pixels and detectors with a wavelength range of $3.5-5 \mu \mathrm{m}$. The integration time was $1500 \mu s$ and the acquisition frequency was set to $150 \mathrm{~Hz}$. The noise equivalent temperature difference (NETD) of the camera, i.e. the thermal resolution, equals $20 \mathrm{mK}$ for a temperature range of $5-40$ degrees $C$. Here, as the temperature varied between about 23 degrees $C$ and 95 degrees $C$, two temperature ranges were used $(5-60$ degrees $C$ and $60-125$ degrees $C)$ and the NETD of the camera does not exceed $30 \mathrm{mK}$. The temperature measurements were recorded in two files. Therefore, the variation of the temperature over the course of the test had to be reconstructed from these two files. In order to ensure that the internal temperature of the camera was stabilized to perform the measurements, it was set up and switched on for one hour before the experiment started. This camera temperature stabilization was necessary to avoid any drift in the measurements during the test.

\section{Results}

As mentioned above, the test was composed of two steps. The first was the stretching of the notched sample at room temperature in order to obtain crystallized crack tips. The second consisted in applying a heat source inside the crack. During the test, images were recorded by kinematic and thermal cameras in order to link the changes in the kinematic field to the temperature at each point of the sample surface. In the following, the effect of temperature 
on the kinematic field is discussed with respect to the variations in stretch ratio and in temperature at points $\mathrm{A}, \mathrm{B}, \mathrm{C}$ and $\mathrm{D}$ (see Figure 1).

\subsection{Kinematic field at the stretched crack tip}

In order to generate crystallites at the crack tips, the sample is first stretched at a nominal stretch ratio of 1.88 . Figure 2 shows the kinematic fields obtained using the DIC technique in terms of displacement and stretch ratio in the loading direction. The reference image corresponds to the undeformed state and the current image corresponds to the sample geometry at the end of stretching. The results presented relate to the deformed sample geometry. This figure highlights the fact that the local stretch ratio at the crack tip exceeds 1.64 , i.e. the stretch ratio at which crystallization begins. A contrario, the stretch ratio obtained at points $\mathrm{B}$ and $\mathrm{D}$ is close to 1 . This is explained by the fact that these zones are located on either side of the stretched crack tips and are therefore relaxed.

\subsection{Effect of temperature}

Once the sample is stretched, the displacement of the moving grip is halted and remains fixed. A heat source is then applied to the circular crack. Figure 3 gives the temperature cartography at the sample surface when the temperature reaches a maximum value of 95 degrees $C$ at the crack tips. This figure shows that the temperature iso-values correspond to quasi-circular lines. The temperature gradient between the crack tip and the edge of the specimen is about 50 degrees $C$ (from 95 to 45 degrees $C$ ). This is a good illustration of 
the poor thermal conductivity of rubbers. It should be noted that the maximum temperature value in the vicinity of the crack during each thermal cycle exceeds or is close to 80 degrees $C$, i.e. 93.9 degrees $C$ at point $\mathrm{A}$ and 78 degrees $C$ at point $\mathrm{B}$. This means that all the crystallites have melted in this zone, whatever the stretch ratio level (Marchal, 2006).

In order to evaluate the effect of temperature variation on the change in the kinematic field, the temperature variation at points $\mathrm{A}$ and $\mathrm{B}$ and the stretch ratio at points $\mathrm{A}, \mathrm{B}, \mathrm{C}$ and $\mathrm{D}$ are considered. In the following, the stretch ratio considered is that calculated in the loading direction. Figure 4 gives the results obtained. First, the temperature at point B is lower than that at point A because the hole is not exactly circular and also because in this zone the metallic cylinder is not in contact with the crack lip. Thus, a part of the heat brought by the heated cylinder is lost by convection. Second, analyzing precisely the variation in the kinematic field related to the variation in temperature by using the absolute value of the stretch ratio seems difficult. This is the reason why the relative stretch ratio is used in the following. This relative stretch ratio is calculated by considering the end of the stretching step as the reference deformation state. Thus, the relative stretch ratio at the beginning of the thermal cycles equals 1. Figure 5 presents the diagram obtained. First of all, in the relaxed zones $\mathrm{B}$ and $\mathrm{D}$ the relative stretch ratio increases with the increase in temperature and decreases with the decrease in temperature, whatever the thermal cycle considered. This phenomenon highlights the effect of the variation in internal energy, which is of the first order, compared to that of the variation in entropy. Let us now consider the zones whose stretch ratio is higher and more particularly higher than 1.64 (points A and C), which is the stretch ratio at the beginning of crystallization. At this level of stretch 
ratio, the previous phenomenon is reversed and the increase in temperature is expected to decrease the stretch ratio. As shown by the magnification of the outlined zone, this is observed at the beginning of the first thermal cycle for temperatures lower than approximately 63 degrees $C$. However, for higher temperatures, the stretch ratio increases. In fact, this phenomenon is due to the crystallites' melting. Indeed, crystallites act as fillers and tend to reinforced material stiffness by the contraction and orientation of the polymer chains (Chenal et al., 2007). The melting of crystallites thus increases the stretch ratio, and at the end of the temperature increase, the stretch ratio at points $\mathrm{A}$ and $\mathrm{C}$ is higher than that at the end of stretching, because all the crystallites have melted. When heat generation is stopped, the temperature at points $\mathrm{A}$ and $\mathrm{C}$ decreases and the stretch ratio increases due to entropic effects. As a consequence, the stress level also decreases in this zone, the test being performed under controlled displacement. Without additional stretching or mechanical cycles, the same quantity of crystallites can not be regenerated when the thermal cycle is reconducted. Thus, the increase in temperature leads to a decrease in stretch ratio and vice-versa. It should be noted that the stretch ratio level is not exactly the same at points A and C. This is explained by the fact that the rubber cut, and more particularly in the zone corresponding to the crack tip, is not perfectly symmetrical. Moreover, in terms of pixels, points $\mathrm{A}$ and $\mathrm{C}$ are not at exactly the same distance from the crack tips.

\section{Conclusion and perspectives}

This study has investigated the effect of temperature variation at the crystallized crack tip in carbon black-filled natural rubber, and more particularly the 
changes in the kinematic field with respect to the temperature. To this end, kinematic and thermal fields were simultaneously measured. In such a material, with a heterogeneous kinematic field, temperature variation accounts for the competition between energy and entropy effects. This was clearly observed in terms of evolution in the kinematic field. Indeed, in relaxed zones, the stretch ratio increases with the increase in temperature, whereas it decreases in highly stretched crack tips. Moreover at crack tips and more generally in crystallized zones, crystallite melting increases the stretch ratio. This is explained by the fact that crystallites act as fillers, concentrating the stress and therefore increasing the apparent stiffness of the material. In fine, such a study could be an interesting way to improve and validate physical thermomechanical models, taking into account the effect of crystallization and crystallite melting in the thermomechanical response of rubbers.

In the future, by coupling kinematic and thermal field measurements, the heat source calculation should enable us to improve the identification and the understanding of the phenomena involved in crack growth.

\section{Acknowledgements}

The authors thank Dr. X. Balandraud, N. Blanchard and H. Perrin for their collaboration. 


\section{References}

Chenal, J.-M., Gauthier, C., Chazeau, L., Guy, L., and Bomal, Y. (2007). Parameters governing strain induced crystallization in filled natural rubber. Polymer, 48, 6893-6901.

Gent, A. N. and Pulford, C. (1984). Micromechanics of fracture in elastomers. Journal of Materials Science, 19, 3612-3619.

Gent, A. N., Lindley, P. B., and Thomas, A. G. (1964). Cut growth and fatigue of rubbers. i. the relationship between cut growth and fatigue. Journal of Applied Polymer Science, 8, 455-466.

Gent, A. N., Razzaghi-Kashani, M., and Hamed, G. R. (2003). Why do cracks turn sideways? Rubber Chemistry and Technology, 76, 122-131.

Greensmith, H. W. (1956). Rupture of rubber - iv - tear properties of vulcanizated containig carbon black. Journal of Polymer Science, 21, 175-187.

Greensmith, H. W. and Thomas, A. G. (1956). Rupture of rubber - iii determination of tear properties. Rubber Chemistry and Technology, 29, $372-381$.

Hamed, G. R., Kim, H. J., and Gent, A. N. (1996). Cut growth in vulcanizates of natural rubber cis-polybutadiene and a 50/50 blend during single and repeated extension. Rubber Chemistry and Technology, 69, 807-818.

Le Cam, J.-B. and Toussaint, E. (2008). Volume variation in stretched natural rubber: competition between cavitation and stress-induced crystallization. Macromolecules, 41, 7579-7583.

Le Cam, J.-B. and Toussaint, E. (2009). Cyclic volume changes in rubbers. Mechanics of Materials, 41, 898-901.

Marchal, J. (2006). Cristallisation des caoutchoucs chargés et non chargés sous contrainte : Effet sur les chaînes amorphes. PhD Thesis, Université 
Paris XI Orsay, France.

Rivlin, R. S. and Thomas, A. G. (1953). Rupture of rubber. I.Characteristic energy for tearing. Journal of Polymer Science, 10, 291-318.

Thomas, A. G. (1958). Rupture of rubber - v - cut growth in natural rubber vulcanizates. Journal of Polymer Science, 31, 467-480.

Thomas, A. G. (1960). Rupture of rubber - vi - further experiments on the tear criterion. Journal of Polymer Science, 3, 168-174.

Vacher, P., Dumoulin, S., Morestin, F., and Mguil-Touchal, S. (1999). Bidimensional strain measurement using digital images. Proceedings of the Institution of Mechanical Engineers. Part C: Journal of Mechanical Engineering Science, 213. 
List of tables

Table 1: Material formulation and mechanical properties Table 1

Material formulation and mechanical properties

Material formulation $(p h r)$ Thermomechanical properties

\begin{tabular}{lccc}
\hline natural rubber & 100 & shore A hardness & 58 \\
zinc oxyde & 9.85 & stretch ratio at break (\%) & 635 \\
oil & 3 & stress at break (MPa) & 22.9 \\
carbon black & 34 & density & \\
sulfur & 3 & & \\
stearic acid & 3 & & \\
antioxidant & 2 & & \\
accelerator & 4 & & \\
\hline
\end{tabular}


List of Figures

Figure 1: Schematic view of sample geometry in the undeformed (left) and deformed (right) states

Figure 2: Kinematic fields after stretching the sample (a) displacement in the loading direction (b) stretch ratio in the loading direction

Figure 3: Cartography of sample surface temperature

Figure 4: Absolute stretch ratio in zone A, B, C, and D, and temperature in zone $\mathrm{A}$ and $\mathrm{B}$ versus time

Figure 5: Relative stretch ratio in zone A, B, C, and D, and temperature in zone $\mathrm{A}$ and $\mathrm{B}$ versus time 


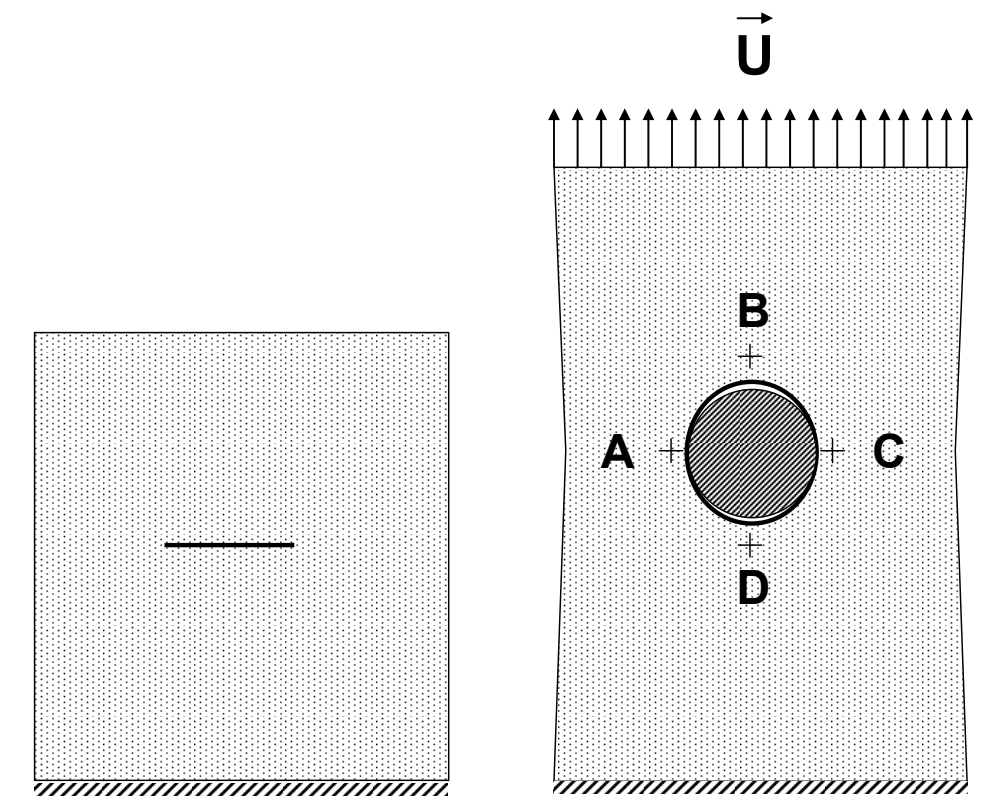

Fig. 1. Schematic view of sample geometry in the undeformed (left) and deformed (right) states 


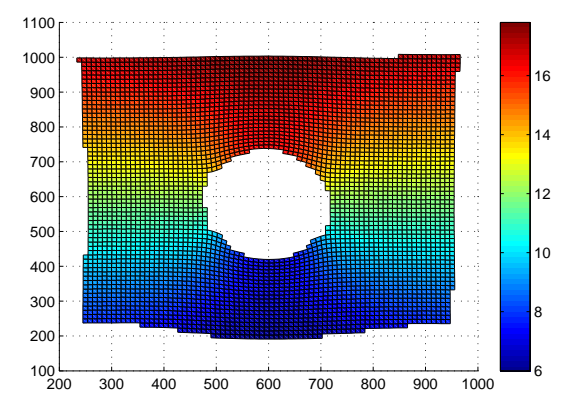

(a) displacement in the loading direction (mm)

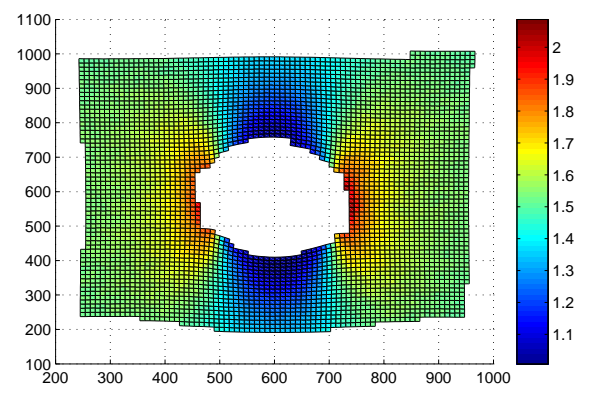

(b) stretch ratio in the loading direction

Fig. 2. Kinematic fields after stretching the sample 


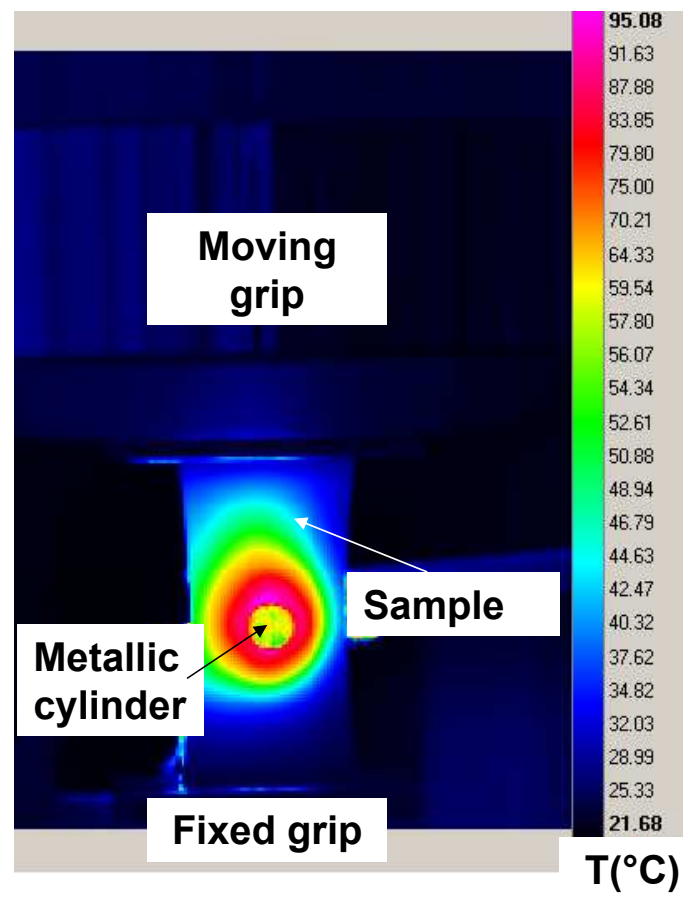

Fig. 3. Cartography of sample surface temperature 


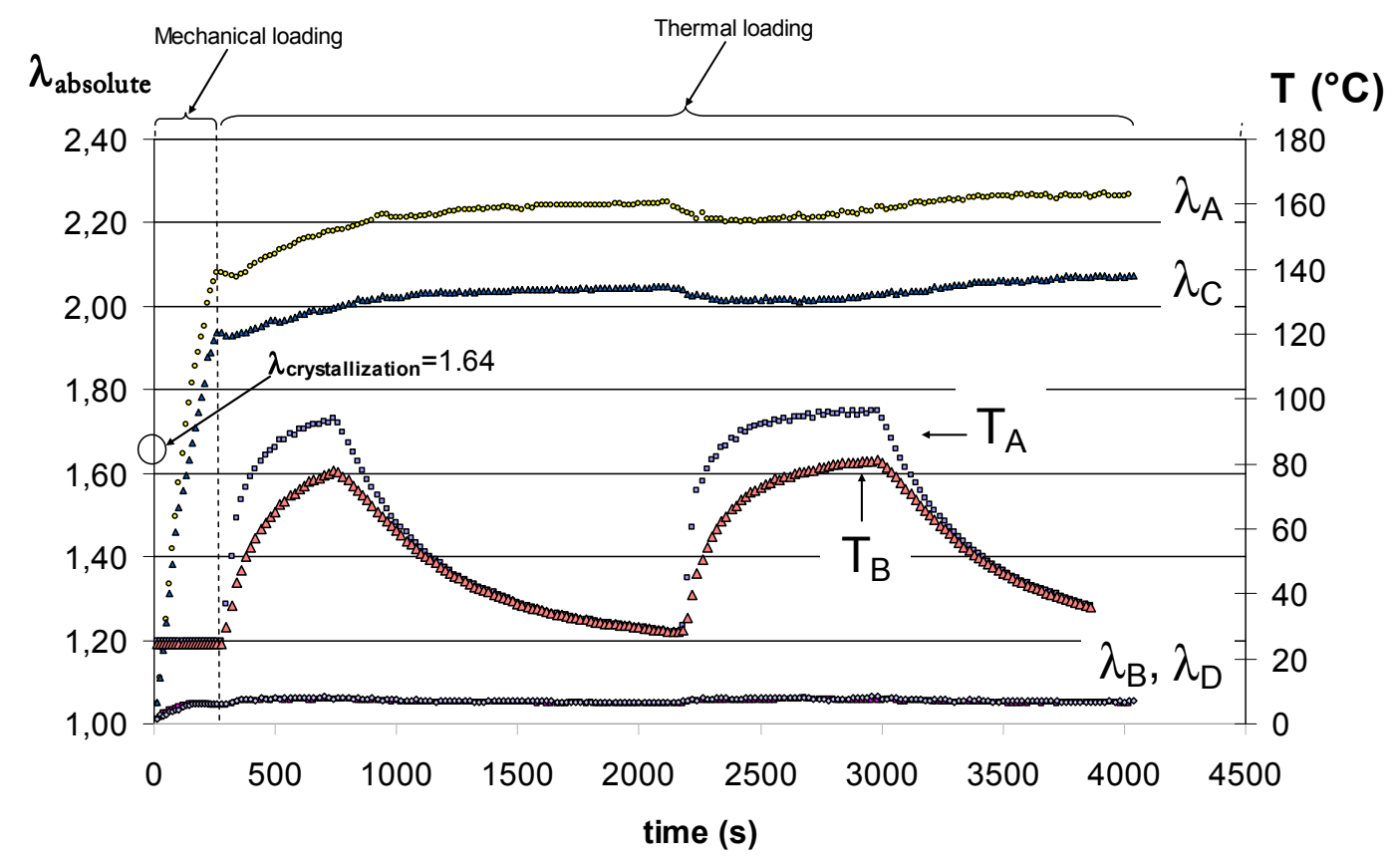

Fig. 4. Absolute stretch ratio in zone A, B, C, and D, and temperature in zone A and $\mathrm{B}$ versus time 


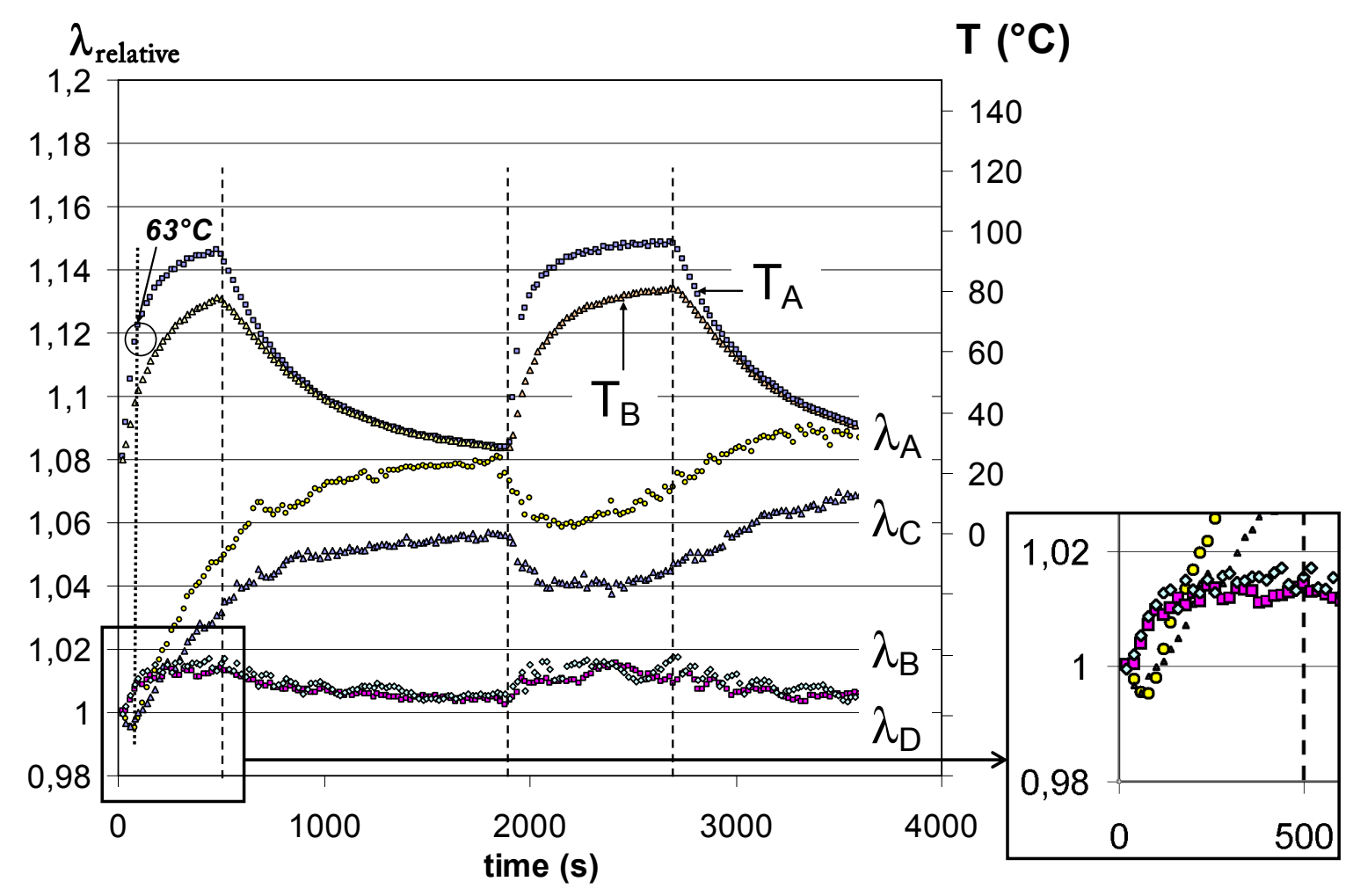

Fig. 5. Relative stretch ratio in zone A, B, C, and D, and temperature in zone A and $\mathrm{B}$ versus time 